American Journal of Pharmaceutical Education 2019; 83 (1) Article 7210.

\title{
COMMENTARY
}

\section{Faculty Applicants' Attempt to Inflate CVs Using Predatory Journals}

\author{
Brooks B. Pond, PhD, Stacy D. Brown, PhD, David W. Stewart, PharmD, David S. Roane, PhD, \\ Sam Harirforoosh, PharmD, PhD \\ Bill Gatton College of Pharmacy, East Tennessee State University, Johnson City, Tennessee \\ Submitted June 13, 2018; accepted August 22, 2018; published February 2019.
}

\begin{abstract}
Recently, scientific publishing has experienced an expansion of journals and publishers whose primary goal is profit and whose peer review process is virtually non-existent. These "predatory" or "opportunistic" journals pose a threat to the credibility and integrity of legitimate scientific literature, and quality science. Unfortunately, many scientists choose to publish in these journals and/or serve on their editorial boards, either due to ease of rapid publication or naivety. Here, we highlight the extensive use of predatory publications or editorial board involvement by applicants applying for a faculty position in the Pharmaceutical Sciences department at the Bill Gatton College of Pharmacy at East Tennessee State University. We caution search committees at other pharmacy schools to thoroughly examine applicant curricula vitarum (CVs) for predatory publishing.
\end{abstract}

Keywords: faculty, journals, predatory, pharmacy, applicants

Online, open-access publishing has a number of benefits, including a broad scope and unparalleled transparency. However, just as phishing and spam followed the introduction of email, predatory journals have followed online, open-access publishing. To be clear, not all online, open-access publishing is predatory; predatory journals are problematic in academic literature, ${ }^{1}$ as their publishers appear to "aim to generate as much revenue as possible, often foregoing a proper peer review." 2 These journals often adopt seemingly authoritative titles, which could sound as lofty as "Proceedings of the National Academy of Pharmaceutical Sciences," and promise eager young authors ease of publication. In reality, peer review may be non-existent and page charges run into the thousands of dollars. In addition to ersatz journals, predatory publishers offer titles on editorial boards that amount to little more than participation awards and undermine the time commitment required for true academic service and scholarship. Librarian Jeffrey Beall of the University of Colorado has taken great strides to alert the scientific community to the problem of predatory publishing. Beall began a blog containing a list of ostensibly peerreviewed journals that charged high fees for rapid online publication. In a 2013 interview with The New York Times, Beall noted that list contained 20 journal titles in 2010 and had grown to 300 by $2013 .{ }^{3}$ The last update to Beall's list in

Corresponding Author: Sam Harirforoosh, Department of Pharmaceutical Sciences, Bill Gatton College of Pharmacy, East Tennessee State University, Box 70594, Johnson City, TN 37614-1708. Tel: 423-439-2074. Fax: 423-439-6350.

E-mail: harirfor@etsu.edu
May 2018 included almost 1,600 suspected predatory journals and 1,200 predatory publishers. ${ }^{4,5}$ It is believed that the true number of these journals may be between 2,000 and 8,000 , publishing, on average, 400,000 papers per year. ${ }^{6}$

Clearly, predatory journals represent a threat to the academic integrity of scientific literature; however, the unscrupulous industry of predatory publishing is persistent. Unfortunately, this industry represents a highly unregulated area. Jeffrey Beall added journals to his list based upon his own individual evaluation, which left him vulnerable to counter-attack. ${ }^{7}$ In response, he withdrew his blog from the web, although the archived version is still available and is being updated by an anonymous post-doctoral researcher., ${ }^{4,5}$ Others have also made concerted efforts to draw attention to the problems in scientific publishing. For instance, John Bohannon, a contributing correspondent for Science, constructed a manuscript containing "outrageous" experiments and nonsensical conclusions authored by a fictitious scientist at a nonexistent university. ${ }^{8}$ Even a cursory review of such an article should have led to rejection. However, various versions of the manuscript were accepted for publication (with a fee) in 157 journals. In a more recent study, researchers from the Department of Psychology at the University of Wroclaw in Poland created a woefully unqualified colleague "Anna $\mathrm{O}$. Szust" (oszust is Polish for "a fraud") and applied to be a potential editor for 360 journals: 120 journals with an official impact factor as indexed on Journal Citation Reports (JCR), 120 journals included on the Directory of Open Access Journals (DOAJ), and 120 from Beall's list. ${ }^{9}$ Forty-eight journals 


\section{American Journal of Pharmaceutical Education 2019; 83 (1) Article 7210.}

accepted "Dr. Szust" as an editor, none from the JCR, 8 journals from DOAJ, and 40 journals from Beall's list.

Predatory journals pose a threat to the integrity of legitimate scientific publications, as they undermine the authenticity of the process of attaining quality peer reviews. ${ }^{10}$ Unfortunately, these journals have now infiltrated the pharmaceutical sciences field. In a recent article published in the Journal of Clinical Pharmacology, Greenblatt and Bertino refer to the journals as "opportunistic" and warn researchers about their email solicitations and their "look alike" names. ${ }^{6}$ For instance, the opportunistic Journal of Pharmaceutics and Pharmacology sounds quite like the Wiley journal, Journal of Pharmacy and Pharmacology. Unfortunately, some scientific researchers choose to publish in these journals and/or serve as members of their "editorial boards," and in doing so, participate in the weakening of scientific rigor. This commentary will discuss the extent to which faculty applicants capitalize on the predatory journal industry to inflate their curriculum vitae (CV).

The Bill Gatton College of Pharmacy at East Tennessee State University (ETSU) established a search committee for the 2017-2018 academic year to fill a vacant position in the Department of Pharmaceutical Sciences. Requirements for the position included an earned $\mathrm{PhD}$ or completion of a $\mathrm{PhD}$ prior to beginning the position in pharmaceutical (or biomedical) sciences with preference in the area of Pharmaceutics, and a record of and/or potential for excellence in teaching, service, and scholarly activity in these areas. The position was advertised in several ways, including the websites for Academic Keys, Chronicle for Higher Education, American Association of Colleges of Pharmacy (AACP), American Association of Pharmaceutical Scientists (AAPS), Insight into Diversity, HigherEdJobs.com, and ETSU's own website, eJobs. Applicants were asked to include a cover letter, $\mathrm{CV}$, research statement, and a teaching philosophy as part of their application. Over the course of the year, 40 potential candidates applied for the position.

During the 2017-2018 academic year, the committee recommended that nine applicants be initially interviewed via web conferencing, and five of those applicants were selected for on-site interviews. However, during the review of the applications, it was noted that some faculty applicants listed publications on their CV in journals that members of the committee identified as predatory. In addition, several faculty applicants listed "serving" on editorial boards of these journals. To assess the extent to which faculty applicants used these journals for publications and/or editorial board service, the committee examined the publication and editorial board lists for each faculty applicant. Among 1,028 publications, 181 papers $(17.6 \%)$ were published in journals that were either referenced on Beall's list or whose publisher was included on
Beall's list. Additionally, of the 141 total editorial boards that were listed on applicant CVs, 91 (64.5\%) were affiliated with publishers of predatory journals. Of the 40 applicants, nine were identified as having $50 \%$ or more of their publications in predatory journals, and three had more than $80 \%$ of their publications in these journals. It should be noted that Beall's list is not a perfect metric by which to judge these publications. Some journals have been placed on Beall's list and removed after members of the academic community argued for the validity of their peer-review processes, while it is likely that many others are predatory, yet not included on the list. ${ }^{11}$ However, the use of these likely predatory journals by faculty applicants, either due to naivety or ease of publication, is troubling.

In a previous faculty search at our college, the search committee identified evidence of plagiarism in the applications of faculty applicants, particularly in their teaching philosophy statements. ${ }^{12}$ The search committee chose to publish the findings in an effort to warn other college faculty to examine materials submitted by faculty applicants for plagiarism. Here, we hope to offer additional caution to committees when examining the CVs of faculty applicants. In a few recent papers published in pharmacy journals, authors urge scientists not to support these opportunistic journals by refusing to submit manuscripts to them, attend their conferences, review manuscripts for them, or serve on their editorial boards. ${ }^{6,10}$ In this commentary, we encourage pharmacy schools to include a discussion of predatory publishing as part of the mentoring program for faculty. Junior faculty should be warned not to fall victim to phishing emails they may receive from these predatory journals. When faculty are evaluating potential journals, a review of Beall's list for journals and publishers would be helpful. Faculty should evaluate journals or editors listed with great scrutiny and recognize the possibility of these journals to be predatory, and that publishing in these journals or serving on their editorial boards could be viewed negatively by their peers. Additionally, when submitting manuscripts for publication, faculty should check to see that the chosen journal is included in the JCR and/or is indexed on PubMed, Science Direct, or other reputable site, even though these sites may include some predatory journals. ${ }^{13}$ In addition, as scholars committed to maintaining the integrity of our disciplines, we suggest that faculty search committees evaluate faculty applicant CVs for enhancement through publishing in predatory journals. Candidates with significant numbers of publications in suspect journals should be assessed closely. Additionally, faculty applicant profiles should be analyzed using a variety of resources, such as those provided by Google Scholar, Web of Science, and consider looking at metrics such as the h-index and 


\section{American Journal of Pharmaceutical Education 2019; 83 (1) Article 7210.}

i10 index, with the understanding that any cataloging system may be contaminated to some degree. ${ }^{10}$ Finally, committees could consider including in job descriptions a statement that indicates publication in journals deemed predatory and/or participation on similar editorial boards may be grounds for ineligibility.

\section{REFERENCES}

1. Deprez EE, Chen C. Medical journals have a fake news problem. Bloomberg Businessweek. 2017.

2. Beall J. What I learned from predatory publishers. Biochem Med (Zagreb). 2017;27(2):273-278.

3. Kolata G. Scientific articles accepted (personal checks, too). The New York Times, 2013.

4. Beall's list of standalone journals. http://beallslist.weebly.com/ standalone-journals.html. Accessed June 13, 2018.

5. Beall's list of predatory publishers. http://beallslist.weebly.com/. Accessed June 13, 2018.

6. Greenblatt DJ, Bertino JS, Jr. Opportunistic journals in the clinical pharmacology space: a policy statement from the publications and public policy committees of the American College of Clinical Pharmacology. Clin Pharmacol Drug Dev. 2018;58(5):567-571. 7. Mimouni M, Braun E, Mimouni FB, Mimouni D, Blumental EZ. Beall's list removed: what stands between us and open access predators? Am J Med. 2017;130(8):e371-e372.

8. Bohannon J. Who's afraid of peer review? Science. 2013; 342(6154):60-65.

9. Sorokowski P, Kulczycki E, Sorokowska A, Pisanski K. Predatory journals recruit fake editor. Nature. 2017;543(7646):481-483.

10. Bowman JD. Predatory publishing, questionable peer review, and fraudulent conferences. Am J Pharm Educ. 2014;78(10):

Article 176.

11. Watson R. Beall's list of predatory open access journals: RIPWatson-2017- Nursing Open-Wiley Online Library. NursingOpen. 2017;4(2):60.

12. Harirforoosh S, Bossaer JB, Brown SD, Pond BB, Ramsauer VP, Roane DS. Plagiarism among applicants for faculty positions. Am J Pharm Educ. 2011;75(10):Article 211.

13. Manca A, Martinez G, Cugusi L, Dragone D, Dvir Z, Deriu F. The surge of predatory open-access in neurosciences and neurology. Neuroscience. June 14, 2017;353:166-173. 